\title{
Entrepreneurship
}

Jan a Jun $2018-$ v.2 - n.1

ISSN: 2595-4318

This article is also available online at: www.sustenere.co

\section{A recolocação do idoso no mercado de trabalho: percepção dos graduandos em administração da Faculdade Maurício de Nassau}

A pesquisa trata-se de um assunto que diz respeito a todos e aborda uma nova inclusão social, onde a sociedade brasileira, diante de um mundo globalizado e economicamente capitalista, estabelece padrões, como a faixa etária na inserção do profissional no mercado de trabalho. Por ser um problema atual, onde muitos idosos necessitam trabalhar, e, ao tentarem se recolocar no mercado de trabalho, acabam tendo bastante dificuldade, assim optou-se por verificar qual a visão de futuros administradores diante dessa questão, além de buscar a verificação se estes "jovens" estão preparados para o cenário que se apresenta em relação ao mercado de trabalho e a terceira idade. Para isso, realizou-se uma pesquisa junto aos alunos do curso de Administração da Faculdade Maurício de Nassau na Unidade Aracaju/SE. Utilizou-se como ferramenta um questionário estruturado contendo 15 perguntas abertas e fechadas a fim de analisar quantitativa e qualitativamente as respostas fornecidas. Como forma de análise, foi realizada estatística descritiva, bem como análise de discurso.

Palavras-chave: Idosos; Mercado de Trabalho; Aposentadoria

\section{Replacement of the elderly in the labor market: perceptions of graduates in management at the Faculdade Maurício de Nassau}

The research is a matter that concerns all and addresses a new social inclusion, where Brazilian society, facing a globalized and economically capitalist world, establishes standards, such as the age group in the insertion of professionals in the labor market. Because it is a current problem, where many older people need to work, and when they try to get back into the job market, they end up having a lot of difficulty, so we opted to check the vision of future managers on this issue, these "young people" are prepared for the scenario that presents itself in relation to the labor market and the old age. For this, a research was carried out with the students of the Administration course of the Mauricio de Nassau Faculty in the Aracaju / SE Unit. A structured questionnaire containing 15 open and closed questions was used as tool to analyze quantitatively and qualitatively the answers provided. As a form of analysis, we performed descriptive statistics as well as discourse analysis.

Keywords: Elderly People; Labour Market; Retirement.

Topic: Recursos Humanos

Reviewed anonymously in the process of blind peer.
Received: $\mathbf{1 1 / 0 1 / 2 0 1 8}$

Approved: 22/04/2018
Keila Oliveira dos Santos

Faculdade Maurício de Nassau, Brasil

http://lattes.cnpq.br/0458846723943995

keylla.olveira17@gmail.com

Tatiane Heinemann Böhmer

Instituto Federal de Sergipe, Brasil

http://lattes.cnpq.br/5481836411575976

tatianebohmer@gmail.com
Referencing this:

SANTOS, K. O.; BÖHMER, T. H.. A recolocação do idoso no mercado de trabalho: percepção dos graduandos em administração da Faculdade Maurício de Nassau. Entrepreneurship, v.2, n.1, p.1-9, 2019. DOI:
http://doi.org/10.6008/CBPC2595-4318.2018.001.0001
DOI: 10.6008/CBPC2595-4318.2018.001.0001 


\section{INTRODUÇÃO}

Éramos apenas 2 milhões de brasileiros em 1950, com 60 anos ou mais. No Censo, realizado em 2000, a população brasileira com 60 anos ou mais totalizou 14,5 milhões e, até 2025 , chegue a ser bem mais. A população de idosos teve um grande crescimento, passando de 3,3\%, em 1991, para 4,3\%, em 2000, e 5,8\%, em 2010 (IBGE, 2010). Segundo as projeções da Organização Mundial de Saúde (OMS), seremos 32 milhões de pessoas com 60 anos ou mais. A OMS ainda revela que o número de pessoas com 60 anos ou mais no mundo triplicará até 2050, e até lá o mundo terá em torno de 2 bilhões de idosos. O Brasil, que em 1950 tinha a 16a maior população de idosos do mundo passará, em 2025, a ser o sexto país com maior população em número de idosos. A transição demográfica brasileira, sem paralelo tiveram início nos séculos XIX e XX, e prosseguirão na maior parte do século XXI. Essas mudanças demográficas dão-se a passagem de altos para baixos níveis de mortalidade e fecundidade que vem acontecendo desde 1960. Segundo o IBGE (2010), existe uma demanda quase obsoleta por funcionários com mais de 40 anos e essa nova inclusão social já deveria estar ocorrendo, pois, o Brasil possui atualmente $80 \%$ de sua população acima de 20 anos.

$\mathrm{O}$ velho, por não se constituir em mão-de-obra apta para o trabalho, é desvalorizado e abandonado pelo Estado e pela sociedade. A miséria e a exclusão que acompanham vastos segmentos da população brasileira se tornaram mais amargas na velhice. (DEBERT, 1999)

A mão de obra com experiência agregada contribuirá muito para as organizações, é certo afirmar que um funcionário da terceira idade não poderá realizar atividades que exigem além de sua capacidade física, porém existem outras competências que podem suprir essa desvantagem. Resiliência, determinação, atenção aos detalhes, simpatia, empatia e cordialidade são algumas das características essenciais para um bom funcionário, e todas essas características são facilmente encontradas na terceira idade, apesar de estarem na fase na qual devem desfrutar dos benefícios trabalhados por toda uma vida, essas experiências não podem ser esquecidas. Albornoz (2004), enfatiza que "no mundo industrial falta o vínculo entre o trabalho e o resto da vida, assim muitas vezes se separa totalmente o trabalho do prazer, da renovação, do preenchimento e da satisfação".

O envelhecimento da população tem proporções significativas, e várias mudanças já estão sendo reconhecidas de modo altamente positivo. Como foi abordado anteriormente, a população da terceira idade possui qualidades das quais foram adquiridas com passar dos anos, acumulando experiência e conhecimento, que são desconhecidas pelos jovens, assim quando o idoso entra novamente no mercado de trabalho, ele tem a possibilidade de interagir e participar da vida social, saindo da esfera de retraimento a que subjugarse, tendo a oportunidade de convívio com pessoas de outras idades, sendo assim uma das maiores vantagens para o idoso. Dessa forma pode-se visualizar um novo aspecto de sociedade idosa, onde eles ainda estão aptos para exercer o seu papel de colaborador, havendo proatividade, aperfeiçoamento e capacidade de geração de emprego, onde trabalho e renda não são vistos como mero resultado do crescimento econômico. Além de ver quais as vantagens da crescente inserção no mercado de trabalho para os idosos, vai ser possível saber que benefícios o empregador tem nesse novo cenário. Porém, ainda não se sabe como a sociedade irá 
reagir a esse fato, sendo assim, como se dá a recolocação do idoso e qual o seu impacto no mercado de trabalho.

Contudo, salienta-se a oportunidade de divulgar e discutir os passos da população de idosos onde vem aumentando gradativamente, apontando a autonomia do sujeito como prioridade dentro das vertentes de trabalho formal, informal e voluntário, prestados com satisfação e dignidade. Já que o país tem a missão irrecorrível de fazer a reforma da previdência social, também lhe cabe pensar alternativas de melhoria para o mercado de trabalho, em especial para a terceira idade.

Ainda que não se outorgue às políticas de adaptação, que buscam gerir os impactos da redução da fecundidade e aumento do envelhecimento populacional em geral, em realidade, precisa-se encontrar maneiras de possibilitar um envelhecimento ativo, de impulsionar e apoiar os idosos sem enxergá-los com uma carga para sociedade.

Esta pesquisa é relevante, pois será a realidade do Brasil nos próximos 33 anos, para os idosos e suas respectivas famílias, ou até mesmo para as próprias organizações, então saber lidar com essa nova situação, melhorando a qualidade de vida do idoso na sociedade, é essencial.

Dessa forma podemos dizer que a maioria dos idosos ainda são capazes de exercerem a sua função de colaborador normalmente, sabendo-se que existem algumas limitações pelo fato da idade avançada, mas não significa que não possam executá-las. A sociedade atual crê que isso é um abuso físico, pois justamente quando a pessoa está perto de se aposentar, o empregador já começa a procurar alguém para preencher a vaga, mesmo sabendo que, o qual está para sair da empresa, possui conhecimentos apurados com relação com ao que vai entrar.

Neste trabalho analisou-se quais critérios o idoso enfrenta ao buscar a recolocação no mercado de trabalho, na percepção dos alunos de administração, através de pesquisa de campo, com o benefício de salientar a oportunidade, divulgando e discutindo os passos dos alunos, futuros administradores e gestores, enumerando fatores que contribuem para que o idoso continue a exercer suas atividades profissionais, identificar as dificuldades que o idoso possui, em voltar ao mercado de trabalho, e apurar de que forma as organizações trabalham a inserção da terceira idade e como esses futuros profissionais estão se preparando para enfrentar o cenário que se apresenta.

\section{REVISÃO TEÓRICA}

\section{Conceito de Idosos}

O conceito de idosos nos denota várias etapas que a velhice apresenta, pois, envelhecer, segundo Mendes (2005), é um meio natural evidenciado por mudanças físicas, mudanças nos sistemas e órgãos corporais principalmente em suas células transparecendo em sua pele, mudanças psicológicas a redução da capacidade intelectual, capacidade de aprendizagem e desempenho da memória, ou seja, na desvalorização social, já que o idoso está se afastando de suas atividades laborais. Já Dias (2007) alega que envelhecer é um processo que envolve diversos fatores, isto é, cada indivíduo tem seu próprio modo de envelhecer. Contudo 
Sá (2002) declara que "o idoso é um ser de seu espaço e de seu tempo. É o resultado de seu processo de desenvolvimento, do seu curso de vida". Logo, expressa Messy (1999), "se envelhece conforme se vive".

Estes respectivos conceitos são diversas formas de ver que o envelhecimento é o resultado de uma qualidade de vida, quando o indivíduo tem a sua posição na vida dentro do contexto, de sua cultura e de seus valores mantendo a autonomia e a independência, no qual os idosos dão conta de suas dificuldades e das perdas que podem ocorrer, porém, simultaneamente, buscam alternativas para equilibrar a saúde física e mental. Segundo o Estatuto do Idoso, em seu art. 80 "O envelhecimento é um direito personalíssimo e a sua proteção, um direito social [...]" (BRASIL, 2003). Consequentemente, a qualidade de vida deixa de estar relacionada a idade cronológica e passa a ser entendida como a capacidade do organismo de corresponder às necessidades da vida cotidiana, buscando objetivos e novas conquistas pessoais e familiares.

E com o aumento de números de idosos no Brasil, a expectativa de vida do brasileiro também aumentou para as mulheres uma esperança de vida um pouco maior de 3 meses e 4 dias, passando de 78,8 anos, em 2014, para 79,1 anos, em 2015. Já os homens têm a expectativa de vida em torno de 71,9 anos, com um aumento um pouco mais que 3 meses e 22 dias, saindo dos 71,6 anos do ano anterior, conforme o IBGE (2015).

\section{Idoso e o Mercado De Trabalho}

O mundo capitalista resume de certa forma o ser humano em um agente produtivo, a importância do homem se dá dentro da sociedade a partir daquilo que ele produz, e quando o idoso se aposenta e encerra suas atividades profissionais, consequentemente, ele vai saindo do núcleo de atividades e pouco a pouco afasta-se de tudo que construiu ao longo da vida, perdendo o vínculo com a sociedade, a partir disso, o aumento da idade é acompanhado por desvalorização e exclusão, fazendo com que a vida deixe de fazer sentido. O mercado de trabalho não compreende como utilizar a capacidade dessas pessoas com idade mais avançada, apesar de elas desejarem permanecer como agentes produtivos.

Nesse sentido, os indivíduos, que ainda permanecem ativos no mercado de trabalho, suas principais razões para continuarem atuando são de sentir-se produtivo, manter-se inserido na sociedade, levando conhecimento de sua experiência de vida para o seu trabalho, ajudar a família, e sobrepondo-se à necessidade financeira onde quase sempre é insuficiente. E entre os idosos que continuam trabalhando, mesmo depois da aposentadoria, a maioria, 17\% são profissionais autônomo, outros $10 \%$ são trabalhadores informais ou fazem algum tipo de bicos, enquanto $2,1 \%$ são profissionais liberais, restando então os que são funcionários de empresas privadas que somam $1,7 \%$.

Art. 26. O idoso tem direito ao exercício de atividade profissional, respeitadas suas condições físicas, intelectuais e psíquicas.

Art. 27. Na admissão do idoso em qualquer trabalho ou emprego, é vedada a discriminação e a fixação de limite máximo de idade, inclusive para concursos, ressalvados os casos em que a natureza do cargo o exigir. (BRASIL, 2003)

Pesquisas revelam que se o Brasil criasse instrumentos para ampliar a empregabilidade dos mais velhos, poderia aumentar seu PIB em 18,2 bilhões de reais por ano (LINS, 2017). O mercado de trabalho não 
é suficientemente eficaz para comportar todo o contingente de pessoas disponíveis para trabalhar, portanto, uma pesquisa do SPC Brasil (2016) mostra que 70,7\% dos aposentados que ainda trabalham têm sentimentos positivos sobre a situação. Entre esses indivíduos, 38,6\% dizem que sentem satisfação pessoal por trabalhar, enquanto $18,7 \%$ dizem que sentem orgulho. Já outros $27,3 \%$ relatam sentimentos negativos sobre a necessidade de trabalhar após a aposentadoria. Entre eles, 8,3\% dizem sentir indignação pela situação, enquanto outros $7,1 \%$ reclamam de cansaço.

Ainda assim, o mercado de trabalho, mostra-se preconceituoso, limitando-se as vagas por idade para a ocupação de alguns cargos, causando todo um contratempo para aqueles que estão atrás de uma recolocação no mercado de trabalho.

Segundo Giatti et al. (2003), foi realizado um estudo com 2.886 idosos de 65 anos ou mais, residentes em dez regiões metropolitanas brasileiras, onde constatou-se que a maioria deles $(68,46 \%)$ estavam aposentados e não trabalhavam, $26,9 \%$ trabalhavam (sendo estes aposentados ou não) e 4,6\% não trabalhavam e nem eram aposentados. Dessa forma, um ponto a ser considerado para a chance de manutenção do idoso no mercado de trabalho, após a aposentadoria, é seu nível de escolaridade e qualificação profissional, podendo propiciar um desenvolvimento contínuo do indivíduo, tanto profissional quanto pessoal, colaborando, assim, com a saúde mental e permanência desse no mercado formal ou informal. Caso contrário, a partir do momento em que se esgota sua força de trabalho, o homem perde um objetivo de vida e acaba aceitando a aposentadoria como um favor, vendo então a aposentadoria como fim de carreira.

\section{Idoso e Aposentadoria}

O Brasil é um dos países da América Latina que assegura uma proteção de previdência básica de renda para grande parte de seus idosos, hoje $80 \%$ dos idosos recebem algum tipo de benefício de renda da previdência, pesquisas relatam que a idade mínima no EUA é de 66 anos, na Alemanha é de 65 anos, no México é de 72 anos, no Chile a idade mínima é de 65 anos, na Coreia do Sul a mínima é de 71 anos e na França a mínima é de 62 anos.

E conforme Camarano (2004), no Brasil existem 4 tipos de benefícios são eles: Aposentadoria Contributiva: é o sistema onde o trabalhador deve ter contribuído no mínimo 25 anos, recebendo valor parcial ou ter contribuído no mínimo 35 anos para receber então o valor integral; Aposentadoria por Idade: a aposentadoria passa a ser lícita para os brasileiros a partir dos 65 anos homens e 60 mulheres. Dados que não tenha nenhum tipo de renda, receberá um salário mínimo, mesmo sem nunca ter contribuído; Aposentadoria Especial: é destinada a trabalhadores expostos às condições prejudiciais à saúde ou à integridade física que tenham trabalhado no mínimo de 15 anos a 25 anos nestas respectivas atividades, ou seja, atividades insalubres e de alta periculosidade, que seja comprovada por um laudo médico (PPP); Aposentadoria por Invalidez: é dada a quem não tem mais como exercer nenhum tipo de atividade remunerada, onde indivíduo é considerado incapaz, e será pago uma renda mensal de $100 \%$ do salário de benefício, inclusive a decorrente de acidente de trabalho enquanto permanecer nessas condições. 
Mesmo sendo o salário base, o benefício previdenciário continua tornando-se bastante representativo na renda total, resumindo-se muito significativo no rendimento domiciliar.

\section{METODOLOGIA}

A presente pesquisa é classificada de natureza qualitativa e exploratória, uma vez que foi definida a análise interpretativa dos dados coletados. Quanto aos fins, como uma pesquisa descritiva, a qual objetiva fornecer ao pesquisador dados sobre as características de grupos, estimar proporções de determinadas características e verificar a existência de relações entre variáveis. Quanto aos meios, é predominantemente de campo, no sentido de ser uma averiguação empírica executada no local onde ocorre certo fenômeno, por meio de um questionário, contendo dados sociodemográficos, visando caracterizar o perfil socioeconômico dos participantes, onde existem perguntas específicas semiestruturadas sobre o objeto de estudo em questão.

O estudo constitui-se em duas turmas de alunos, totalizando 40 alunos, graduandos do curso de Administração, vinculados a Faculdade Maurício de Nassau, unidade Aracaju/SE. Entretanto, não foram adotados critérios específicos de seleção por amostragem, pois a escolha se deu pelo critério de acessibilidade.

Foram excluídos da pesquisa os alunos pertencentes a turma do 8o período, pois fazem parte da turma da pesquisadora, onde entende-se que a mostra estaria comprometida, já que a temática já fora debatida em sala de aula. Também foram excluídos a turma do 4o período por faltarem nos dias onde foram feitas as aplicações da pesquisa.

A pesquisa teve como base o trabalho de campo, assim, foram aplicados questionários semiestruturados, composto de perguntas abertas e fechadas, pelos professores das respectivas turmas, durante o mês de outubro de 2017, a fim de traçar o perfil do aluno e verificar seu ponto de vista em relação a temática estudada.

A pesquisa, pela sua especificidade, assume caráter quanti-qualitativo. Para análise dos dados quantitativos e cruzamentos das ocorrências foram utilizados a Planilha Eletrônica Excel e os dados qualitativos foram submetidos a tratamento diferenciado, no qual as informações obtidas foram listadas e compatibilizadas, sendo agrupadas por conteúdos semelhantes, para assim facilitar a compreensão e análise.

\section{RESULTADOS E DISCUSSÃO}

O gráfico 1 mostra, que grande parte dos entrevistados (95\%), observam que nas organizações onde trabalham, não são desenvolvidas nenhum tipo de ações ou projetos para manter ou inserir a terceira idade em seu quadro de colaboradores. Partindo dessa premissa, pode-se levantar a hipóteses de que as organizações ainda estão se posicionando quanto a inserção do idoso no mercado de trabalho, não estando ainda preparadas para lida com esse panorama. Por não haver interesse por parte das organizações em contratar pessoas dessa faixa etária, torna o cenário ainda mais preocupante e difícil para aqueles que já atingiram a faixa-etária dos 60 anos ou mais. 
Continuar ativo no mercado de trabalho favorece a autoestima de muitas pessoas, então não ser útil nessa idade é difícil de administrar, por isso que passar adiante experiência aos mais jovens é uma expectativa de findar esses preconceitos.

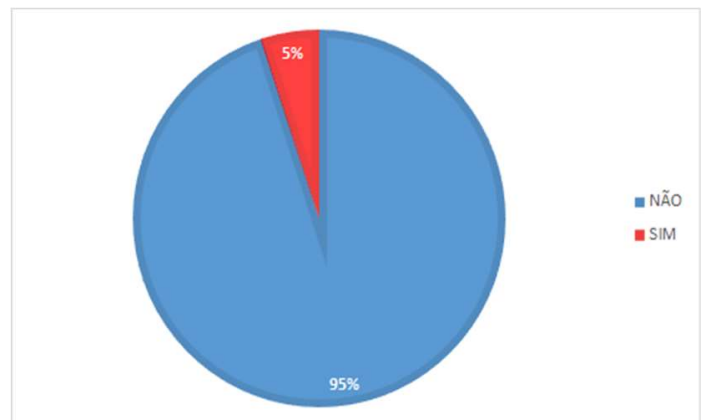

Gráfico 1: Descreve as organizações que possuem ações para a recolocação da terceira idade.

Neste caso os idosos devem investir onde eles mais têm dificuldades, e de acordo com a pesquisa os principais desafios para sua recolocação são: a concorrência e a competitividade; pois $45 \%$ do total dos entrevistados, atua na área de formação.

A qualificação também é considerada um desafio para os idosos, já que $50 \%$ da população idosa no Brasil, com idade acima de 60 anos, possui apenas o ensino fundamental, apenas $26 \%$ das pessoas idosas concluíram o ensino médio, e por fim, somente $12 \%$ da população idosa no Brasil finalizaram o ensino superior, ou seja, alcançaram o diploma universitário, o que dificultando ainda mais a situação das pessoas da terceira idade, já que o mercado de trabalho, na atualidade, com toda essa tecnologia, anda bastante exigente e competitivo.

Outra questão levantada pelos entrevistados é a discriminação e falta de respeito com estes indivíduos, pois, no que se refere o espaço de trabalho onde esses idosos estão inseridos, há essa certa dificuldade enfrentada, por eles, na hora da inserção no mercado de trabalho. Sob a ótica do enfrentamento do preconceito, parte dos participantes da pesquisa afirmam que existem vários fatores relacionados ao preconceito entre jovens e idosos. A atualidade aponta valorizar principalmente os jovens, mesmo sabendo que o envelhecimento é um processo normal e que afeta todos os seres humanos

Entretanto, vislumbra-se uma possível alteração dessa realidade, pois $98 \%$ dos entrevistados responderam que, como gestores, contrataram pessoas com idade de 45 ou mais, e os motivos apontados por vários deles foram a vasta experiência tanto profissional como de vida, além do amplo conhecimento que se adquiriu ao longo de sua carreira.

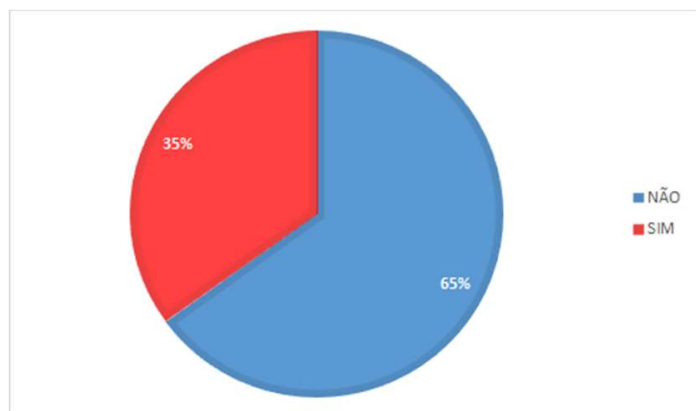

Gráfico 2: Descreve a quantidade de alunos que estão se preparando para a aposentadoria 
A pesquisa revela que $35 \%$ dos entrevistados já estão se preparando para a sua aposentadoria, porém, desses $35 \%$, apenas $12,5 \%$ possui uma previdência privada. A pesquisa ainda nos revela que $82,5 \%$ dos graduandos não apoiam a reforma na previdência, entretanto, dos $82,5 \%$, meramente $38 \%$ conhecem todos os itens desta reforma. Essa informação é bastante alarmante, já que a desinformação impacta diretamente na democracia e na busca pelos direitos dos cidadãos.

No Brasil a aposentadoria, ou seja, a posse de um benefício social, não significa necessariamente que um indivíduo deixe o mercado de trabalho, pois a legislação brasileira permite a volta do aposentado para a atividade econômica sem nenhuma penalidade (CAMARANO, 2004).

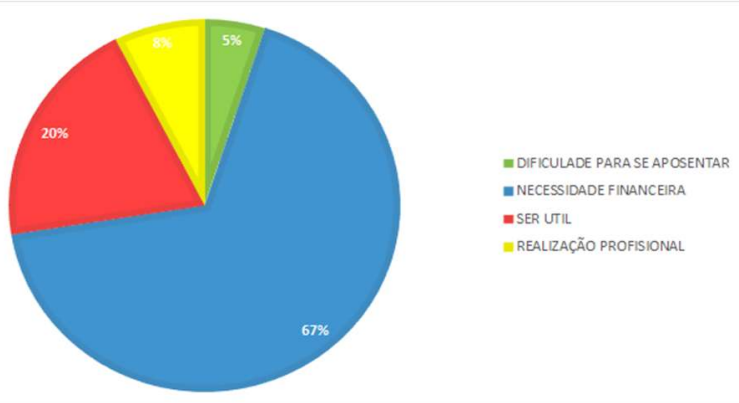

Gráfico 3: Descreve os motivos que levam o profissional idoso a continuar trabalhando.

Quanto à questão do retorno do idoso no mercado de trabalho, a maioria dos entrevistados concordar com o retorno das pessoas de idade superior a 60 anos, com opiniões divergentes sobe a motivação, seja ela com a finalidade de manter-se ocupado, sentir-se útil, aumento de renda, bem-estar emocional e físico, entre outros vários fatores que leva a buscar novamente ou continuar ao trabalho por uma satisfação pessoal.

Das razões apresentadas pelos entrevistados, a dificuldade financeira ficou em primeiro lugar, com $67 \%$, seguida por sentir-se útil, com $20 \%$, pois a importância de se sentir 'útil' na sociedade em que vive é o que dá sentido à vida das pessoas, já que envelhecer não é uma doença, mas uma consequência, sendo o envelhecimento um evento inevitável e irreversível do ser humano (GIATTI et al., 2003).

Sendo assim, constata-se que o retorno do profissional da terceira idade gera benefícios não só para a empresa, mas contribui também para a evolução da sociedade, reduzindo o número de aposentados que necessitam de complementação de renda, ou até mesmo devolvendo sua dignidade e apoio psicológico. Mas, apesar disso, reconhece a existência do preconceito e a exclusão, como obstáculos ao exercício de uma profissão.

\section{CONCLUSÕES}

A sociedade em que vivemos, de forma geral, possui uma visão preconceituosa sobre o processo de envelhecimento, devido aos avanços na área da saúde as pessoas estão vivendo mais e melhor, e é natural também que busquem uma vida ativa, portanto há uma necessidade maior de atenção a essa faixa etária. Principalmente, no que se refere ao mercado de trabalho, pois ainda é muito limitado em relação a vagas e projetos para estes potenciais. 
Portanto, com base nos resultados e na literatura estudada, diante do percurso da pesquisa, observase que parte dos alunos entrevistados vê que o retorno do profissional da terceira idade no mercado de trabalho, gera benefícios não só para a empresa, que terá seu quadro de colaboradores com mais comprometimento, experiência e potencial, com capacidade para fazer uma empresa crescer, mas devido à falta de oportunidade das empresas, os profissionais encontram-se em uma situação de grande dificuldade para continuar ativos no mercado de trabalho, cabe às empresas se organizarem e prepararem para este novo cenário, promovendo um ambiente organizacional que estimule a produtividade e o aproveitamento desse capital intelectual, já que o envelhecimento da população é algo irreversível. Mas também contribui com a evolução da sociedade, seja na perspectiva de ser produtivo, reduzindo o número de aposentados que necessitam de complementação de renda ou até mesmo desenvolvendo sua dignidade.

\section{REFERÊNCIAS}

ALBORNOZ, S.. O que é trabalho. São Paulo: Brasiliense, 2004.

ANJOS, V. S.; GABRIEL, M. S. D.; SANTOS, P. T.; SILVA, A. A. V.; PRADO, P. I.. A Terceira Idade No Mercado De Trabalho. Revista dos Discentes da Faculdade Eça de Queirós, v.5, n.8, 2016.

BRASIL. Lei n.10.741, de 10 de outubro de 2003. Dispõe sobre o Estatuto do Idoso e dá outras providências. Brasília: DOU, 2003.

CAMARANO, A. A.. Os novos idosos brasileiros muito além dos 60?. Rio de Janeiro: IPEA, 2004.

DEBERT, G. G.. O significado da Velhice na sociedade brasileira. Acta Paul Enf, São Paulo, v.12, p.147 -158, 2000.

DIAS, A. M.. O processo de envelhecimento humano e a saúde do idoso nas práticas curriculares do curso de fisioterapia da UNIVALI campus Itajaí: um estudo de caso. Dissertação (Mestrado) - Universidade do Vale do Itajaí, 2007.

GIATTI, L.; BARRETO, S. M.. Trabalho feminino e saúde na terceira idade. Ciência \& Saúde Coletiva, Rio de Janeiro, v.7, n.4, p.825-839, 2002
IBGE. Censo demográfico 2010: resultados da amostra, trabalho, pessoas de 10 anos ou mais de idade com condição de atividade na semana de referência de economicamente ativas e idade de 60 a 69 anos, comparação entre as capitais. Instituto Brasileiro de Geografia e Estatísticas, 2010.

LINS, J.. O potencial dos cabelos grisalhos. Você RH, São Paulo, ed.51, ago-set, 2017.

MENDES, M. R. S. S. B.; GUSMÃO, J.L.; FARO, A. C. M.; LEITE, R. C. B. O.. A situação social do idoso no Brasil: uma breve consideração. Acta Paul Enf, v.18, n.4, p.55-75, 2005.

MESSY, J.. A pessoa idosa não existe. São Paulo: Aleph, 1999.

SÁ, J. L. M.. A formação de recursos humanos em Gerontologia: fundamentos epistemológicos e conceituais. In: FREITAS, E. V.. Tratado de Geriatria e Gerontologia. Rio de Janeiro: Guanabara-Koogan, 2002. p.1119-1124

SANTOS, S. S. C.. Gerontologia á Luz da Complexidade de Edgar Morin. Revista Eletrônico do Mestrado de Educação Ambiental, Rio Grande, p.22-35, 2004.

A CBPC - Companhia Brasileira de Produção Científica (CNPJ: 11.221.422/0001-03) detém os direitos materiais desta publicação. Os direitos referem-se à publicação do trabalho em qualquer parte do mundo, incluindo os direitos às renovações, expansões e disseminações da contribuição, bem como outros direitos subsidiários. Todos os trabalhos publicados eletronicamente poderão posteriormente ser publicados em coletâneas impressas sob coordenação da Sustenere Publishing, da Companhia Brasileira de Produção Científica e seus parceiros autorizados. Os (as) autores (as) preservam os direitos autorais, mas não têm permissão para a publicação da contribuição em outro meio, impresso ou digital, em português ou em tradução. 